
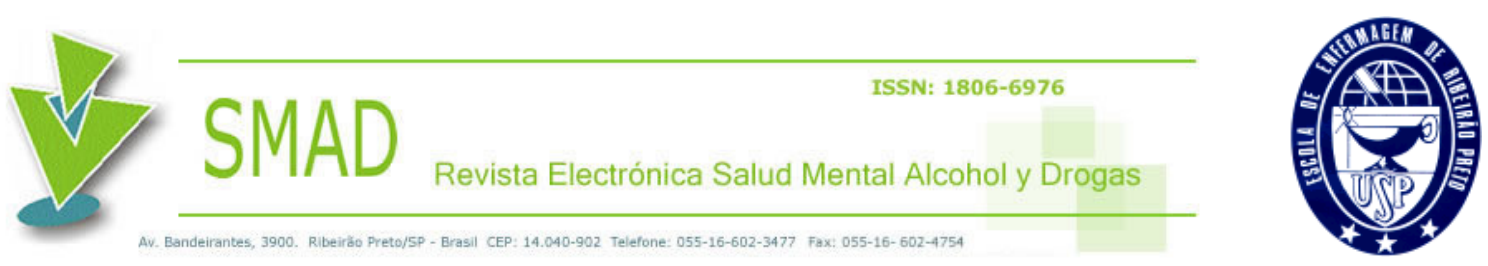

\title{
IMPLICAÇÕES NA SAÚDE MENTAL DE CUIDADORES DE IDOSOS: UMA NECESSIDADE URGENTE DE APOIO FORMAL
}

\section{Renata Cristina Virgolin Ferreira de Camargo ${ }^{1}$}

$\mathrm{O}$ ato de cuidar de idosos dependentes no domicílio, atualmente, é tarefa cada vez mais frequente para as famílias que, nesse cenário, vivenciam contextos de fragilidades física, financeira e social, além de implicações na saúde mental do cuidador. A metodologia adotada é de estudo exploratório-descritivo, com abordagem qualitativa que, pautada na literatura, objetivou contribuir com subsídios teóricos para a melhor compreensão de quem é o cuidador de idosos dependentes e quais implicações impactam o mesmo. Como proposta, o artigo aponta para a importância de se promover políticas públicas de intervenção de cuidado ao cuidador, em diferentes níveis, proporcionando-lhe melhoria do bem-estar, prevenção de conflitos e estresse e segurança na realização dos cuidados prestados.

Descritores: Cuidadores; Idosos Dependentes; Estresse; Saúde Mental.

\section{Implications on the Mental Health of Elderly Caregivers: An Urgent NeEd FOR FORMAL SUPPORT}

Providing care for dependent elderly at home is currently an increasingly common task from families who, in that setting, experience contexts of physical, financial and social fragility, in addition to implications on the mental health of the caregiver. This is an exploratory-descriptive study, performed with a qualitative approach. Based on the literature, the purpose of this study was to contribute with theoretical support to better understand who the caregiver of dependent aged people is, and what implications affect them. As a proposal, the article points at the importance of promoting public policies for care intervention to caregivers at different levels, providing an improvement of their wellbeing, preventing conflicts and stress, and promoting their safety while delivering care.

Descriptors: Caregivers; Frail Elderly; Stress; Mental Health.

\section{IMPLICANCIAS EN LA SALUD MENTAL DE CUIDADORES DE ANCIANOS: UNA NECESIDAD URGENTE DE APOYO FORMAL}

Actualmente, el acto de cuidar ancianos dependientes en el domicilio es una tarea cada vez más frecuente para las familias que, en tal escenario, experimentan contextos de fragilidad física, financiera y social, además de implicancias en la salud mental del cuidador. La metodología adoptada es de estudio exploratorio descriptivo, con abordaje cualitativo que, referido en la literatura, objetivó contribuir con contenidos teóricos para una mejor comprensión de quien es cuidador de ancianos dependientes y de las implicancias que impactan al mismo. Como propuesta, el artículo resalta la importancia de promover políticas públicas intervencionistas de atención al cuidador en diferentes niveles, brindándole mejoras en su bienestar, prevención de conflictos y estrés y seguridad en la práctica de la atención prestada.

Descriptores: Cuidadores; Anciano Frágil; Stress; Salud Mental.

1-Assistente Social da Prefeitura Municipal de Araraquara, com especialização em Saúde Mental pela Universidade de Ribeirão Preto (UNAERP), SP, Brasil.. E-mail: revirgolin@yahoo.com.br

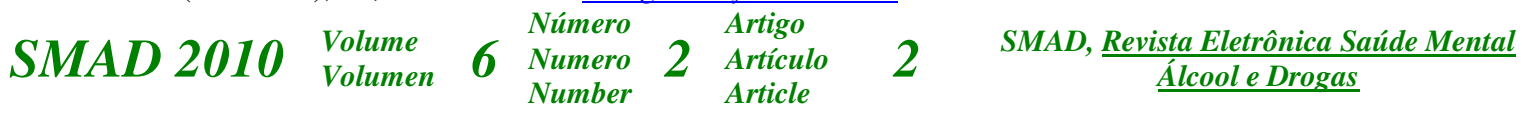



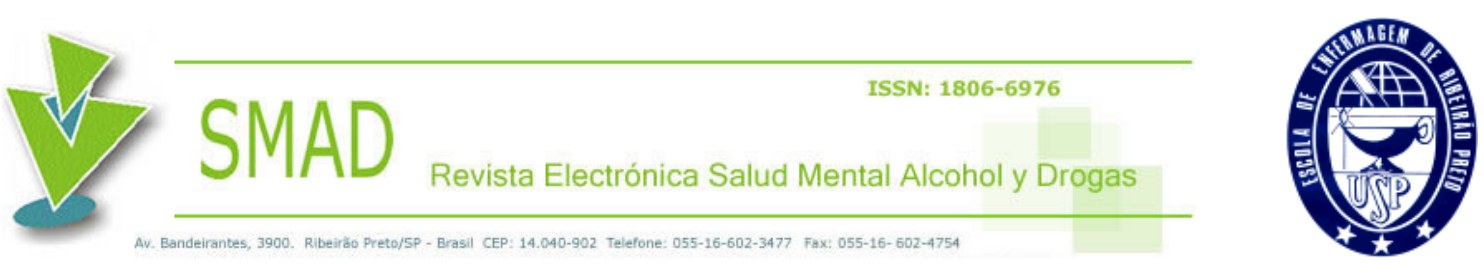

\section{Introdução}

Nas últimas décadas, o grande aumento na incidência do envelhecimento, associado a doenças crônicas e degenerativas, tem despertado a atenção de pesquisadores para evidenciar o contexto familiar e o novo lócus do cuidado. Atualmente, permeiam como desafios ao Sistema Único de Saúde (SUS) a prevenção dessas doenças e o suporte aos cuidadores familiares.

No Brasil, a transição demográfica e a transição epidemiológica apresentam, cada vez mais, quadro de sobrevivência de idosos na dependência de uma ou mais pessoas que supram as suas incapacidades para a realização das atividades de vida diária ${ }^{(1)}$.

Culturalmente, essas pessoas, chamadas cuidadores, são, em sua maioria, mulheres que atuam como protagonistas anônimas nessa nova esfera de cuidados, o domicílio, onde estão presentes também dimensões emocionais e afetivas ${ }^{(2)}$. Sentimentos de desespero, cansaço, ansiedade, angústia, desamparo são frequentes em famílias de cuidadores de doentes crônicos e graves ${ }^{(3)}$.

Essa atribuição de cuidar, comumente, é esperada pela sociedade ${ }^{(4)}$, porém, vale destacar que esses cuidadores são doentes em potencial, e sua capacidade funcional está constantemente em risco, uma vez que são pessoas comuns que, de um momento para outro, se veem na situação de cuidar de alguém que lhes é próximo.

O presente estudo objetivou contribuir com subsídios teóricos para melhor compreensão de quem é o cuidador de idosos, acometidos por doenças crônicas e

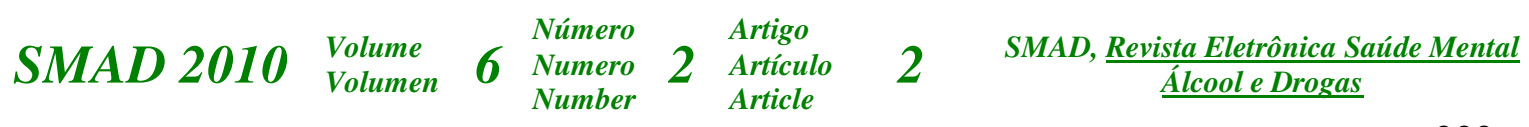



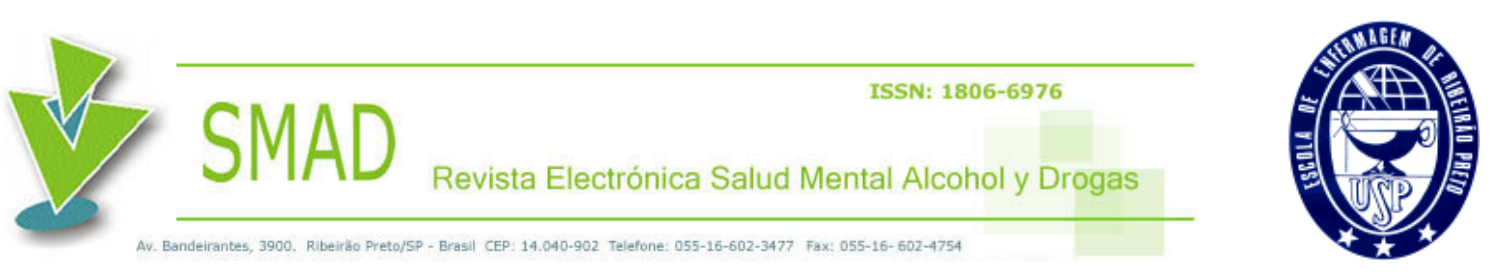

degenerativas, e quais implicações subjetivas do cuidar em família impactam esse cuidador.

A literatura denota evidências de alterações emocionais, físicas e sociais em cuidadores, sendo essencial, nesse processo, ampla estrutura de apoio para enfrentar as diferentes etapas do cuidado. Sendo assim, faz-se necessário apresentar propostas de intervenção, trabalho de acompanhamento, educação em saúde para prevenção de ansiedade dos cuidadores e familiares, ou seja, políticas de proteção focalizadas no cuidador familiar.

O método de pesquisa adotado foi o estudo teórico, cujo ponto de vista da abordagem do problema pode ser considerado como qualitativo, através de objetivos exploratórios, tendo como base o levantamento bibliográfico.

\section{Cuidando de idosos no contexto familiar}

Em virtude do crescimento gradativo do envelhecimento populacional e das mudanças observadas no padrão de morbidade dos idosos, tem crescido a possibilidade de que as famílias venham a se dedicar a esse mister, uma vez que o envelhecimento é fenômeno biológico, psicológico e social, no qual a plenitude do ser humano pode se modificar em relação ao mundo e à sua própria história.

O envelhecimento, quando acompanhado por doenças crônicas e limitações físicas, cognitivas e sociais, impõe às suas famílias questões nunca antes experimentadas na dinâmica das relações ${ }^{(5)}$.

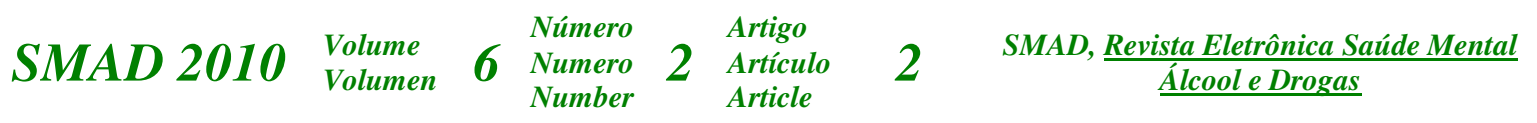



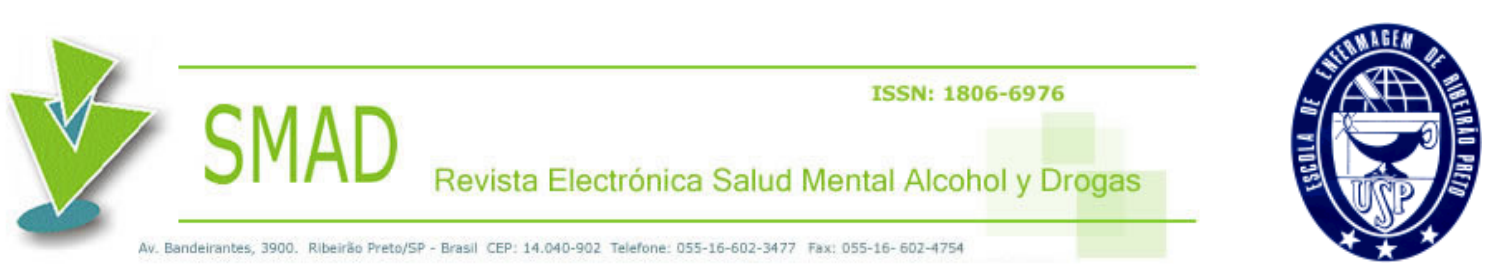

O estado de doença acarreta algumas repercussões psíquicas inevitáveis, como preocupações, angústias, medos, alterações na autoimagem e algum nível de dependência ${ }^{(6)}$. No tocante a essa dependência, pode-se definir como condição do idoso, a qual se caracteriza por degenerescência decorrente de doenças crônicas ou de outras patologias que ameaçam a integridade física, social e econômica, diminuindo ou impedindo a capacidade do indivíduo para atender suas necessidades ${ }^{(7)}$.

Estudos revelam que cerca de $40 \%$ dos indivíduos com 65 anos ou mais de idade precisam de algum tipo de ajuda para realizar pelo menos uma tarefa, como fazer compras, cuidar das finanças, preparar refeições e limpar a casa ${ }^{(8)}$. Uma parcela menor, $10 \%$, requer auxílio para realizar tarefas básicas como tomar banho, vestir-se, ir ao banheiro, alimentarse, sentar e levantar de cadeiras e camas. Para cada idoso de alta dependência que se encontra institucionalizado, há dois sendo cuidados em casa pela família ${ }^{(9-10)}$.

Estima-se, também, que 13\% dos indivíduos, entre 64 e 74 anos, 25\% dos indivíduos, entre 75 e 84 anos, e $46 \%$ daqueles acima de 85 anos apresentam algum tipo de incapacidade $^{(11)}$.

No contexto brasileiro, aproximadamente $85 \%$ dos idosos apresentam pelo menos uma doença crônica e, desses, pelo menos $10 \%$ tem, no mínimo, cinco afecções concomitantes $^{(12)}$. Nos USA, há, aproximadamente, uma em cada quatro famílias (23\% ou 22,4 milhões de famílias) envolvidas em cuidados de pessoas maiores de 50 anos $^{(13-14)}$. Estima-se também que, em 2025, o Brasil terá a sexta maior população de idosos do mundo, cerca de $13,8 \%$ da população composta por essa faixa etária.

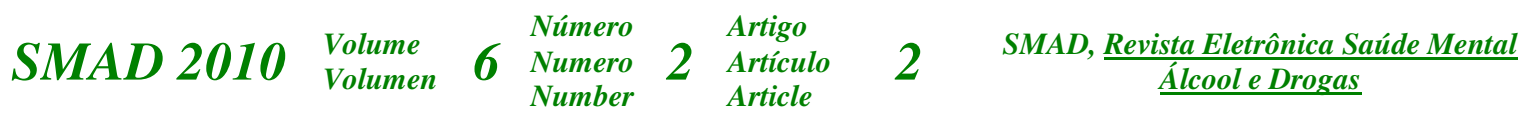



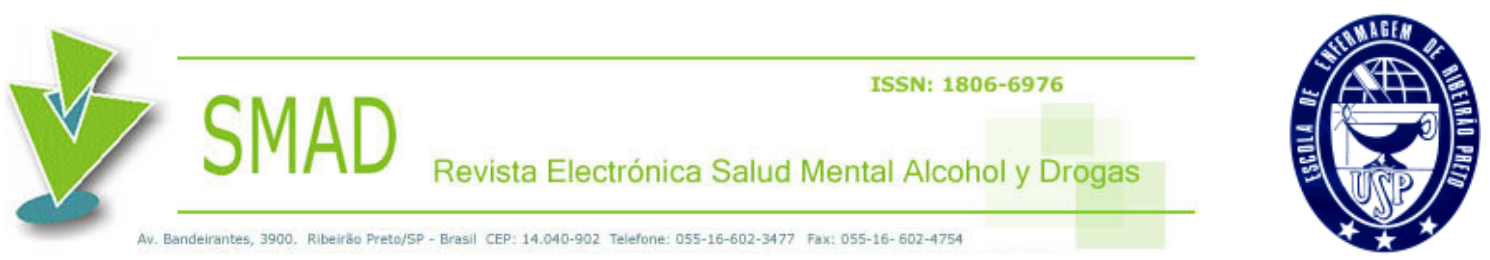

Diante desse novo contexto, destaca-se a figura do cuidador familiar, principal agente do sistema de apoio informal no cuidado ao idoso com problemas de saúde, caracterizando-se como primeiro abrigo e fonte de assistência aos idosos ${ }^{(10,15)}$. Essa ocupação, a de cuidador de idosos, é contemplada pela Classificação Brasileira de Ocupações (CBO), sob código 5162, que define o cuidador como alguém que cuida a partir de objetivos estabelecidos por instituições especializadas ou responsáveis diretos, zelando pelo bem-estar, saúde, alimentação, higiene pessoal, educação, cultura, recreação e lazer da pessoa assistida.

A escolha do cuidador não costuma ser ao acaso e a opção pelos cuidados nem sempre é do cuidador, mas, muitas vezes, expressão de um desejo do paciente, ou falta de outra opção, podendo, também, ocorrer de modo inesperado para um familiar que, ao se sentir responsável, assume esse cuidado, mesmo não se reconhecendo como cuidador ${ }^{(16)}$.

Não obstante, a esse novo papel de cuidar, verifica-se que a maioria o fará sem nenhuma ajuda informal ou formal sistemática. A literatura aponta que boa parte das famílias e das mulheres brasileiras não está preparada, seja por causa dos eventos apontados seja em virtude das pressões econômicas, ocupacionais, familiares e provenientes do sistema de saúde, igualmente despreparado para acolher as necessidades dos idosos e de suas famílias ${ }^{(17)}$.

As famílias, no entanto, são parte integrante da intervenção em saúde em todas as fases do processo saúde e doença, uma vez que a interação desenvolvida entre o cuidado do indivíduo e o contexto familiar tem sido apontada como algo indispensável para o cuidado

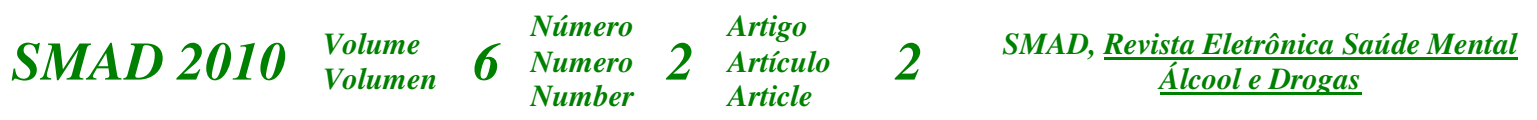



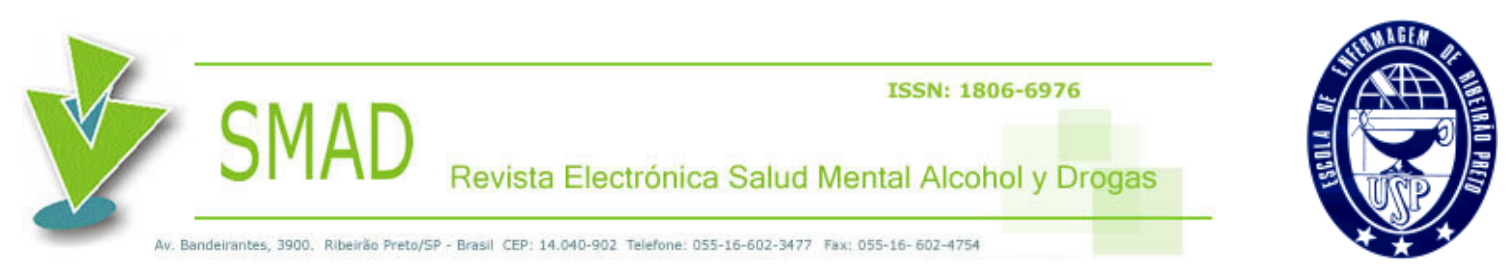

integral da pessoa doente ${ }^{(3)}$. Tomar a família como perspectiva é considerar o contexto familiar no processo de cuidar em saúde não apenas como o local onde o cuidado é dado e recebido durante a vida, mas onde todo um processo de viver a vida e transições da vida está sendo construído a cada dia ${ }^{(18)}$.

No que diz respeito ao perfil do cuidador, a literatura gerontológica mostra que, na grande maioria dos países ocidentais, o desempenho das tarefas de cuidar em família é, geralmente, atribuição feminina, e a idade média, no geral, é de $46 \operatorname{anos}^{(10)}$. A atribuição de papéis e tarefas de cuidar segue normas culturais que esperam do homem o sustento da sobrevivência material da família e a autoridade moral, e, da mulher, a organização da vida familiar, o cuidado dos idosos e tudo o que se relacione à casa. Essa realidade também é presente para as mulheres que trabalham fora, pois, caso não assumam o cuidado, tornamse alvo de pressão social e familiar, surgindo conflitos e sentimentos de culpa.

O cuidado exercido por mulheres é fruto de construções históricas e sociais, determinadas pela divisão sexual do trabalho, e o cuidado tem sido o foco principal de sua atividade e a expectativa da sociedade em relação a elas.

A literatura internacional apresenta quatro fatores presentes na designação da pessoa que assume o cuidado ao idoso dependente: parentesco (cônjuges), gênero (principalmente mulher), proximidade física (vive junto) e proximidade afetiva (conjugal, pais e filhos) ${ }^{(1)}$.

Independente desses fatores, o processo de construção da identidade do cuidador dáse a partir do enfrentamento da rotina de cuidados e da reflexão desencadeada por esse enfrentamento $^{(19)}$. O dia a dia é o espaço de imediato, no qual cuidadores devem funcionar

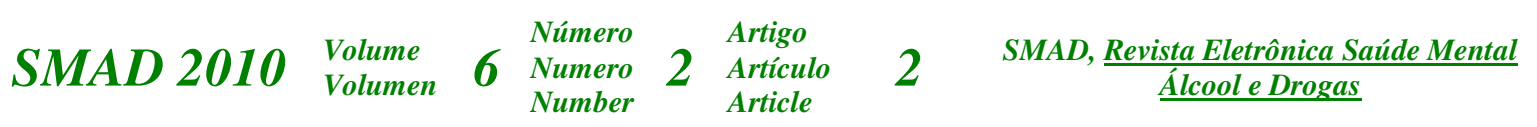



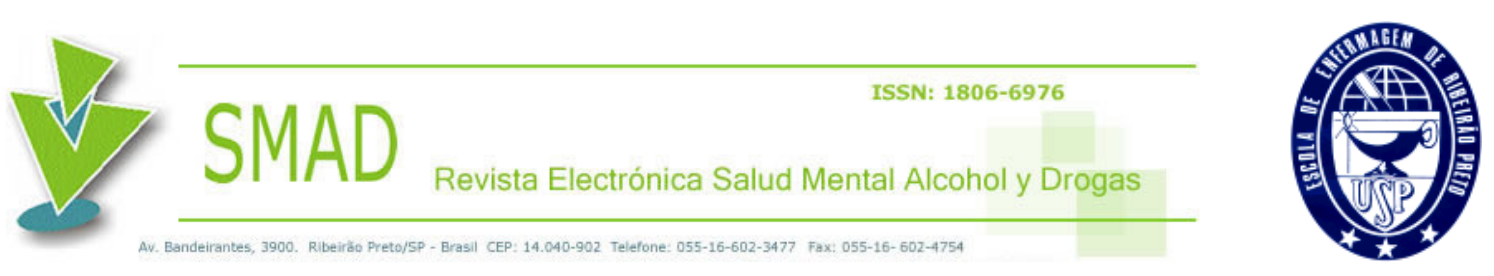

por meio do saber prático.

Vale ressaltar que, além de fatores geracionais, tornar-se cuidador pode depender de outros eventos como morar na mesma casa, ter condições financeiras, dispor de tempo e, principalmente, laços afetivos em relação à pessoa cuidada. Fatores emocionais, motivação, capacidade de doação podem interferir nas tarefas de cuidar.

Os valores culturais e individuais sobre a velhice e o cuidado influenciam também na aceitação dos papéis de cuidar e também na forma de lidar com o processo $^{(20)}$. Ser cuidador principal implica num processo que envolve toda a dinâmica familiar ${ }^{(18)}$, pois, nessa esfera de cuidados não há somente as expectativas, mas, também, os conflitos que são transmitidos multigeracionalmente.

O relacionamento entre o cuidador e o idoso, bem como os esforços cognitivos e comportamentais para lidar com as exigências do cuidar, é afetado por referências sociais, por exemplo, sobre o que é considerado apropriado em dada situação ${ }^{(5,21)}$.

Considerando a atual pluralidade de arranjos familiares, as reações são as mais variadas e refletem também as demandas econômicas e socioculturais ${ }^{(2)}$. Em geral, o cuidador passa a assumir múltiplas funções, tornando-se cuidador único, sendo essa relação dependente da sua história de vida e do aporte familiar.

Estudos apontam que as faces do cuidar, a progressão da incapacidade, a instalação súbita ou gradual da dependência, o prognóstico da moléstia do idoso e os recursos, dos quais o cuidador dispõe para desenvolver suas tarefas, oneram a sua resistência física e psicológica $^{(5)}$. E a redução desses problemas, decorrentes do cuidar, depende em parte da

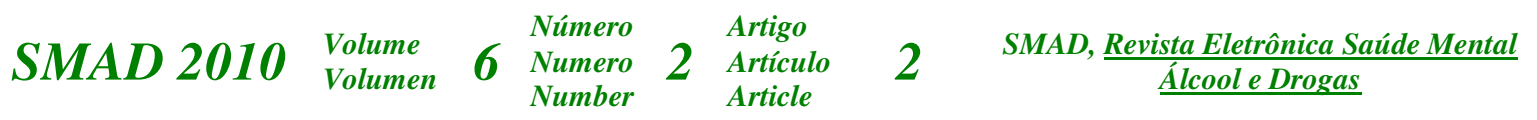



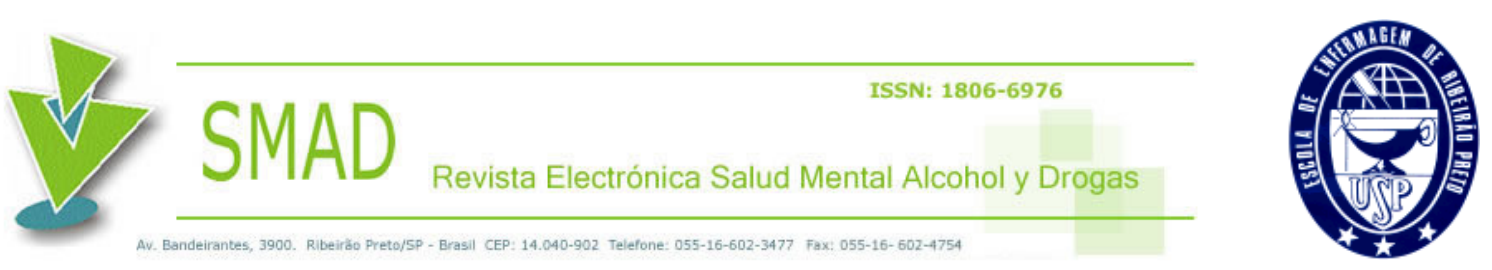

habilidade do cuidador em lidar com várias situações adversas ao mesmo tempo, de compatibilizar tarefas de cuidar com tarefas da casa, de organizar o próprio comportamento e o de outros, de mobilizar recursos pessoais internos e apoios externos e de tomar decisões ${ }^{(5)}$.

O estresse do cuidador: o impacto do prestar cuidados

O cuidado é uma representação de atitudes, de preocupação, de responsabilidade e de envolvimento. No caso de idosos, espera-se que haja alguém capaz de desenvolver ações de ajuda naquilo que esses não podem realizar por si só, assumindo responsabilidades de dar apoio e ajuda para satisfazer suas necessidades, visando a melhoria da condição de vida.

Desempenhar a tarefa de cuidar do idoso no domicílio, no entanto, deflagra diferentes sentimentos que são vivenciados pelos cuidadores diariamente. O cotidiano do cuidado favorece o surgimento de sentimentos de insatisfação por parte do cuidador e a manifestação do seu descontentamento, entre outros motivos, podendo produzir situações de conflito entre ele e o familiar ${ }^{(22)}$.

Atividades que parecem ser simples, para quem as desenvolve, se tornam árduas para quem nunca precisou enfrentá-las. Sendo assim, existem inúmeros estudos referentes ao impacto sobre a família e o ônus para o cuidador, com repercussões físicas, psíquicas, sociais e econômicas sobre os mesmos.

A literatura aponta que as avaliações do cuidador, sobre a situação de cuidar e seus

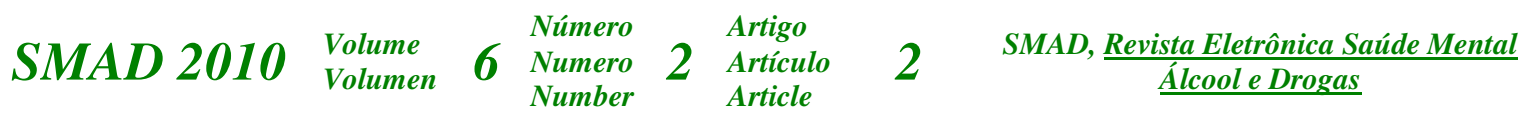



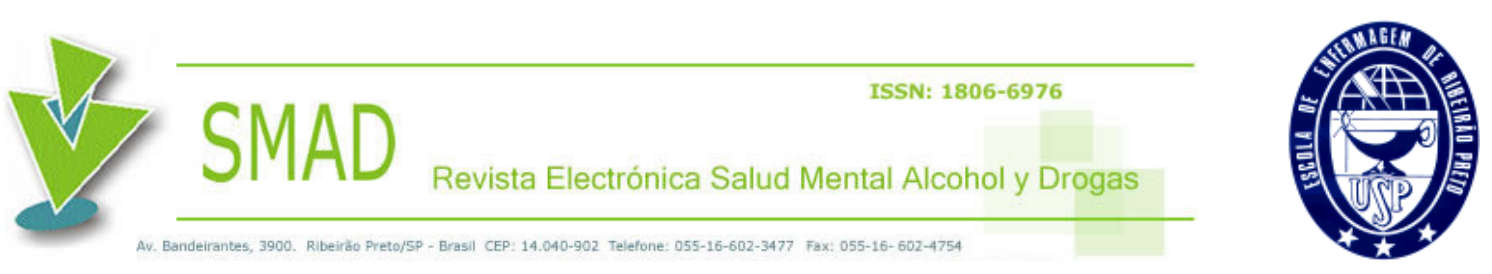

efeitos sobre a saúde física e mental, são resultantes da interação entre a exposição do cuidador aos estressores, sua vulnerabilidade e seus recursos psicológicos e sociais ${ }^{(23-24,10)}$.

Há diferenças entre esses estressores, podendo ser definidos em primários e secundários. Os primários estão relacionados às características do idoso dependente (comprometimento para a realização de atividades de vida diária, déficits cognitivos, alterações no comportamento). Já os estressores secundários estão relacionados ao papel do cuidador (abrangendo conflitos familiares, aspectos econômicos, restrição da vida social e de natureza intrapsíquica) ${ }^{(23)}$.

De acordo com esse modelo, há eventos relacionados ao contexto familiar (de relações pessoais, renda, escolaridade, gênero, idade, saúde, ocupação do cuidador, personalidade, história de relacionamento com o idoso) que desencadeiam os estressores primários e secundários. Cansaço, insônia, irritabilidade, ansiedade, depressão, fragilidade física e psicológica são condições que, somadas ou intensificadas pelos estressores, podem levar o cuidador ao esgotamento e sobrecarga física e mental.

Impacto ou sobrecarga é definido como o estado psicológico que resulta da combinação de trabalho físico, tensão emocional, restrição social e dificuldades financeiras, provenientes da atividade de cuidar ${ }^{(25-26)}$, consequências essas provenientes de práticas variadas e de demandas emocionais do cuidado ${ }^{(27)}$.

Cansaço emocional caracteriza-se pela perda progressiva de energia, fadiga e esgotamento emocional, refletindo a situação em que os trabalhadores não podem dar de si no âmbito afetivo ${ }^{(22,28)}$. É experiência de desgaste psicológico, ocasionado pela assistência

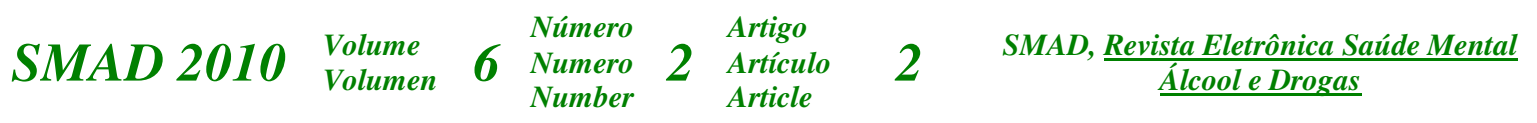



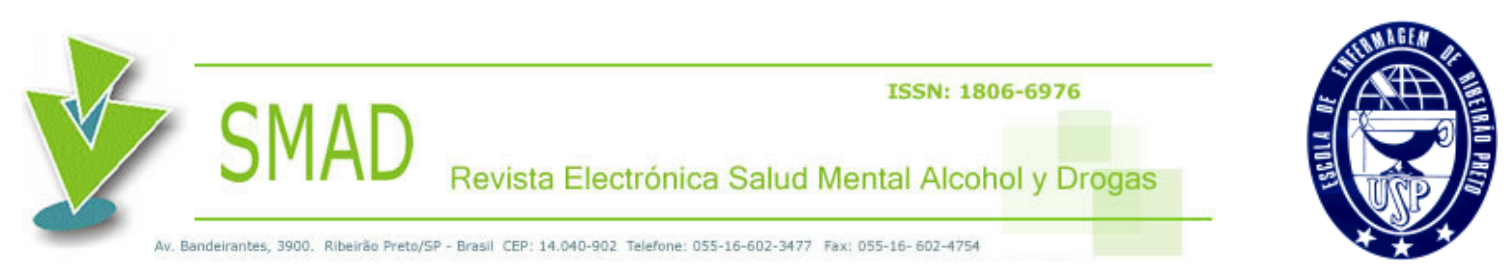

cotidiana prestada a usuários que demandam ajuda, ou seja, um fazer solitário onde são vivenciados conflitos e sentimentos ambivalentes.

Esses momentos solitários fazem com que o cuidador e o idoso se lancem numa relação de busca, querendo (re)montar, (re)fazer, (re)estabilizar uma vida cotidiana nos moldes anteriores, o que já não é mais possível pela necessidade e dependência do idoso para com o cuidado ${ }^{(19)}$.

A literatura também aponta os componentes do impacto objetivo e subjetivo no cuidador. Os componentes do impacto objetivo no cuidador são: sobrecarga financeira, tensão gerada pela necessidade de abandonar as responsabilidades com outras pessoas da família, interrupção nas atividades da rotina doméstica, supervisão excessiva e problemas com vizinhos, além dos componentes do impacto subjetivo, que são: sentimentos de embaraço, sobrecarga, ressentimento e exclusão social ${ }^{(26,29-30)}$.

De modo geral, a literatura resume o estresse do cuidador em: ônus físico e financeiro, que tende a se agravar com a evolução da doença, falta de informações suficientes aos cuidadores para exercer o cuidado, poucos recursos sociais de apoio, escassez de pessoas especializadas que possam dar suporte e poucas fontes de apoio emocional, rivalidade entre a tarefa de cuidar e o trabalho profissional, ou mesmo com o papel familiar desempenhado anteriormente pelos cuidadores, sentimentos negativos que podem aflorar na dinâmica cuidar-ser-cuidado, o cuidar solitário, exercido por um único membro da família sem a ajuda, ou reconhecimento dos outros integrantes ${ }^{(31)}$.

A falta de tempo também é queixa importante, pois, além da diminuição da vida SMAD $2010 \begin{aligned} & \begin{array}{l}\text { Volume } \\ \text { Volumen }\end{array} \\ & \text { Solumero }\end{aligned} \quad \begin{aligned} & \begin{array}{l}\text { Número } \\ \text { Number } \\ \text { Number }\end{array} \\ & 2\end{aligned} \begin{aligned} & \begin{array}{l}\text { Artigo } \\ \text { Artículo } \\ \text { Article }\end{array} \\ & \text { SMAD, Revista Eletrônica Saúde Mental }\end{aligned}$ 

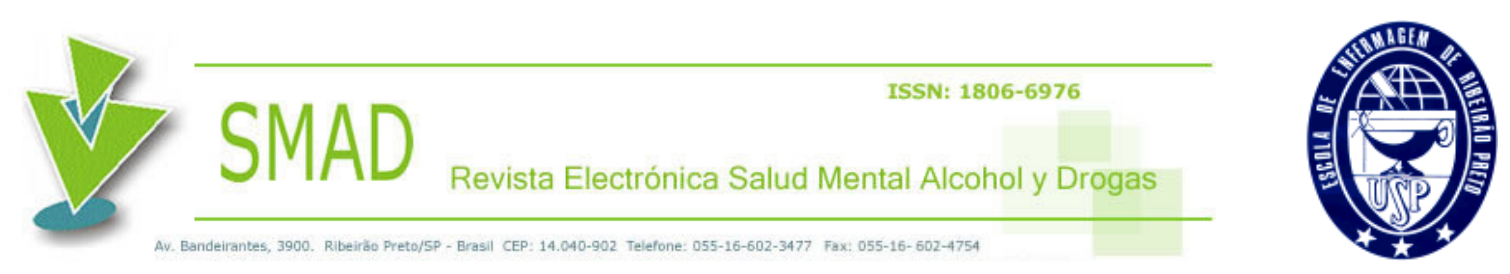

social, o cuidador deixa de cuidar de si mesmo para cuidar do idoso, anulando atividades prazerosas.

Devido à ocorrência gradativa de sintomas de ansiedade e depressão, muitos dos cuidadores acabam se tornando pacientes. Estudos revelam agravamento das fragilidades e doenças crônicas em cuidadores, devido à sobrecarga física ${ }^{(32)}$, pois as demandas do cuidado excedem os limites do esforço físico, mental, psicológico, social e econômico.

Em pesquisa realizada, dentre os 50 cuidadores entrevistados sobre as modificações observadas pelos cuidados em si, após o início das atividades de cuidados, $24 \%$ relataram modificações psicológicas (aumento do estresse, nervoso, angústia e depressão) e 14\% relataram aumento do cansaço e preocupações ${ }^{(3)}$.

Esse efeito, além de perverso, sob o ponto de vista social, acaba por sobrecarregar o sistema público de saúde. É comprovado que quanto menor o nível de suporte social maior é a sobrecarga do cuidador ${ }^{(26)}$.

Quando a família e o cuidador não conseguem encontrar alternativas viáveis, ou quando as habilidades e os recursos familiares são insuficientes para o manejo da situação, há forte tendência para a desorganização familiar e individual, trazendo consequências negativas para o cuidado ao idoso e para o bem-estar do cuidador, uma vez que o próprio processo de envelhecimento da população brasileira está se dando num momento de profunda desordem econômica, deixando, com certeza, a população de baixa renda mais desamparada e carente, demandando posturas compensatórias de apoio a essa realidade ${ }^{(1)}$.

Dar apoio emocional e instrumental, contando com possibilidades mínimas de

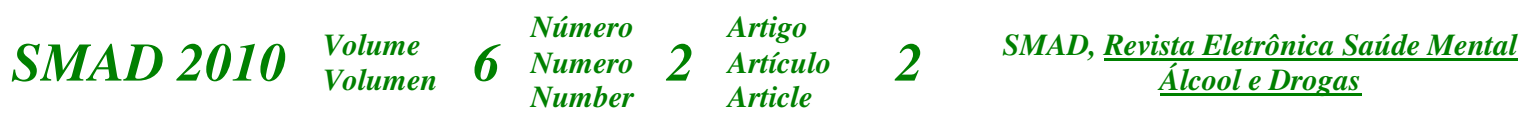



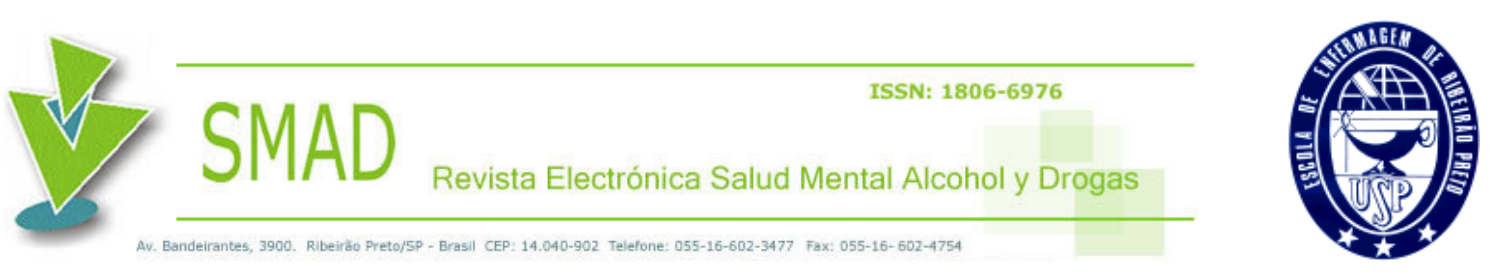

melhora, e sem perspectivas de retribuição, desgasta as reservas físicas e psicológicas dos cuidadores familiares. Estudos apontam que, aproximadamente, de 46 a $59 \%$ dos cuidadores são clinicamente deprimidos, sendo maior a depressão entre as mulheres cuidadoras (49\%) como resultado do cuidar ${ }^{(14,33-34)}$.

Cuidar do idoso no domicílio é tarefa que deve ser preservada e estimulada ${ }^{(1)}$, porém, cuidar de um indivíduo idoso e incapacitado não é tarefa para uma mulher sozinha, sem apoios, nem serviços que possam atender às suas necessidades, e sem política de proteção para o desempenho desse papel. O cuidado no domicilio sustenta-se em relações de intersubjetividades e requer novas modalidades de comunicação, de acordos e de responsabilização que estão sob determinações políticas, econômicas, éticas, sociais e culturais $^{(35)}$.

Cuidando de cuidadores: uma necessidade de compromisso e preocupação política de proteção social

A literatura revela que muitos cuidadores não se veem como tal, isto é, não se reconhecem como ocupantes de um papel social. Ao contrário, veem suas ações como extensão das relações pessoais e familiares ${ }^{(11)}$. As instituições sociais descumprem o seu papel quando se comportam da mesma forma, isto é, não reconhecem que o cuidador familiar não só corresponde a uma demanda objetiva e imediata dos idosos e, assim, cumpre normas sociais de retribuição, mas também oferece solução para um problema que

SMAD $2010 \begin{aligned} & \begin{array}{l}\text { Volume } \\ \text { Volumen }\end{array} \\ & \text { Sulumero }\end{aligned} \quad \begin{aligned} & \begin{array}{l}\text { Número } \\ \text { Number } \\ \text { Number }\end{array} \\ & 2\end{aligned} \begin{aligned} & \begin{array}{l}\text { Artigo } \\ \text { Artículo } \\ \text { Article }\end{array} \\ & \text { SMAD, Revista Eletrônica Saúde Mental }\end{aligned}$ 

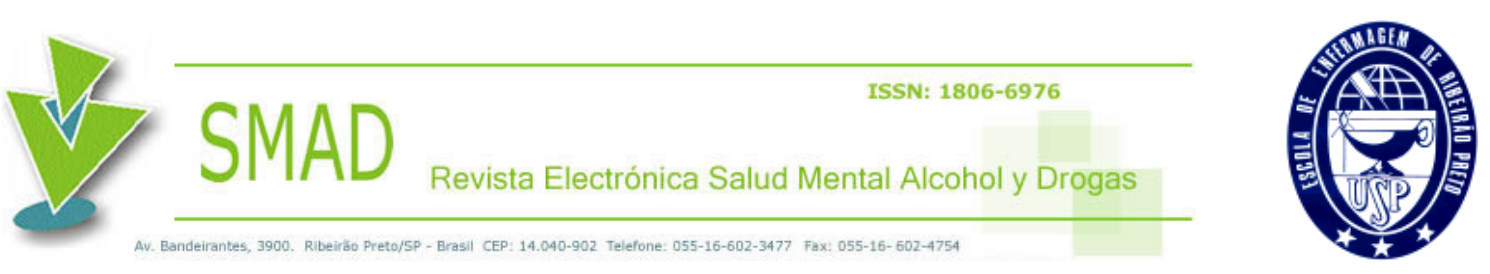

é de toda a sociedade.

Dessa forma, são necessárias intervenções junto aos cuidadores em diferentes níveis (físico, psicológico, social e financeiro) que incluam suporte adequado a fim de que não acarretem sobre os mesmos impactos emocionais. Intervenções essas que enfoquem as questões relacionadas ao papel, às responsabilidades e ao estresse da família e do cuidador, considerando como urgente a necessidade de apoio formal, uma vez que estudos revelam o comprometimento na saúde mental dos cuidadores ${ }^{(19,32,36-37)}$.

Como propostas, existem amortecedores para as pressões externas, anteriormente citadas, como: a ajuda instrumental, cognitiva e emocional oferecida por redes formais e informais de apoio, os conhecimentos e habilidades do cuidador e as estratégias de enfrentamento ${ }^{(10)}$. E o domicílio é espaço privilegiado para o estabelecimento de estratégias de educação permanente, visando a articulação da integralidade, trabalho e educação ${ }^{(38)}$. Além disso, acrescentam-se como mediadores os recursos sociais, incluindo acompanhamento médico e sua opinião em relação ao estado de saúde de seu paciente.

A função do apoio social compreende o nível de recursos fornecidos por outros e pode ser especificada em quatro aspectos: apoio emocional (que envolve expressões de amor e afeição), apoio instrumental (que se refere aos auxílios "concretos", provimento de necessidades materiais em geral, ajuda para trabalhos práticos e ajuda financeira), apoio de informação (aconselhamentos, sugestões, orientações que podem ser usadas para lidar com problemas e sua resolução) e interação social positiva (que compreende a disponibilidade de pessoas com quem é possível se divertir e relaxar).

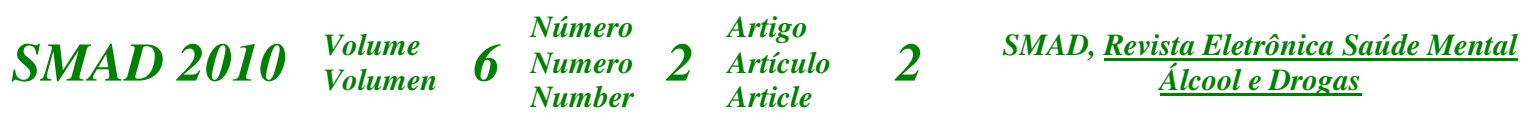



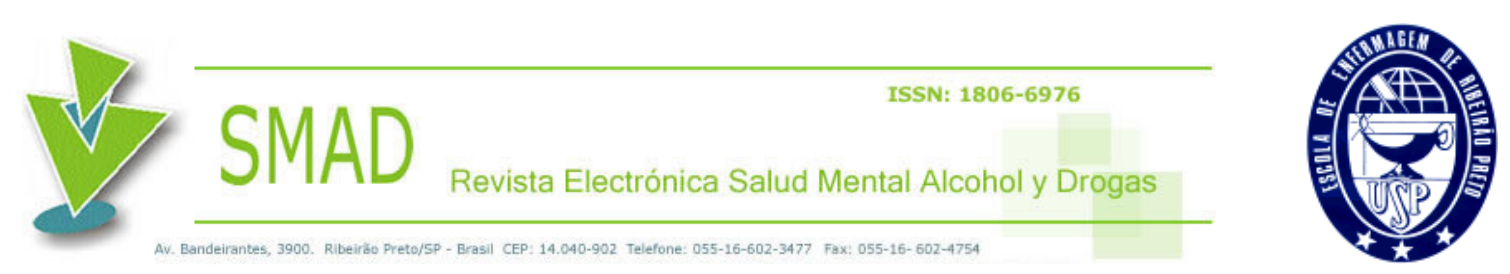

Tais processos podem ser entendidos como estratégias de cuidado ao cuidador e podem ser divididos em três grandes vias: processo educativo e de construção de habilidades junto ao cuidador (oferta de módulos educativos sobre provisão de cuidado no domicílio), estabelecimento de parceria dinâmica com a família, com divisão de responsabilidades, e um canal de comunicação contínuo com o paciente e sua família ${ }^{(16)}$.

Os autores ressaltam, ainda, que a única intervenção capaz de reduzir o ônus será aquela dirigida às necessidades do paciente, com medidas que não imponham sobrecarga adicional ao cuidador, nem impacto significativo sobre suas vidas financeiras. Mas, sim, atividades que visem um modelo participativo, com envolvimento ativo, através de processos educativos permanentes, informativos, com utilização de recursos de divulgação, campanhas, veiculação em propagandas e treinamento de profissionais de saúde.

Afinal, cuidar no domicílio implica em novos modos de fazer e saber dos profissionais de saúde, postura essa que deve primar por efetivar ações que permitam a integralidade, a intersubjetividade e o cuidado direcionado à família ${ }^{(39)}$. Nesse aspecto, igualmente imprescindível é o investimento junto ao corpo clínico dos hospitais, a fim de que possam transferir conhecimentos ao cuidador, como parte do planejamento da alta hospitalar do paciente idoso.

Importante também são os investimentos em Programas de Internação Domiciliar (Lei n.10.424/2002), que tratam de estratégia para a reversão da atenção centrada em hospitais, que propiciem a construção de nova lógica de atenção, com enfoque na promoção e prevenção da saúde e na humanização da atenção. Essa Lei inclui, principalmente, os

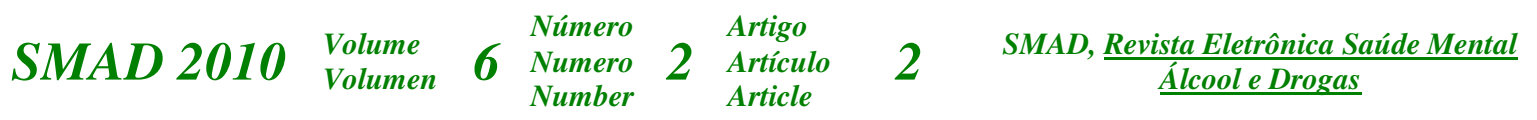



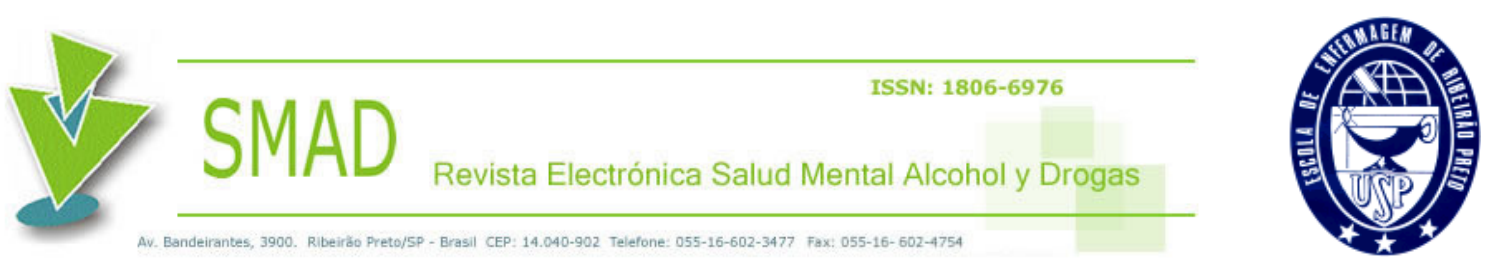

procedimentos médicos, de enfermagem, fisioterapêuticos, psicológicos e de serviço social, necessários ao cuidado integral dos usuários em seu domicilio, pois, além do acompanhamento sistemático, possibilita ao cuidador acesso a informações precisas sobre o diagnóstico e prognóstico da doença, possibilitando que ele se prepare para as necessidades do cuidado.

Existem hoje, no país, várias experiências de internação domiciliar (Santos, SP, Londrina, PR, Hospital de Clínicas da USP-SP, Marília, SP, Hospital Escola de São Carlos, SP, Belo Horizonte, MG), cuja principal característica é o atendimento de idosos com doenças crônicas.

Em pesquisa realizada pelo serviço de atendimento domiciliar em Guarulhos, $\mathrm{SP}^{(11)}$, verificou-se que, do total de 56 cuidadores, $23 \%$ apresentaram mudança positiva no seu estado emocional, após treinamento e acompanhamento da equipe de saúde no domicílio. Esses resultados evidenciam que a saúde mental dos cuidadores pode ser preservada em decorrência dessas condições de apoio formal ${ }^{(24)}$.

Pode-se afirmar que essa estratégia proporciona às famílias apoio institucional em ações estruturadas e contínuas, de monitoria e apoio profissional e de material para a pessoa cuidada, para os cuidadores e para a família, além de beneficiar o próprio Sistema de Saúde, o Estado e a economia, porque reduz o tempo e o número de internações hospitalares $^{(40)}$.

O treinamento de cuidadores familiares de idosos é área de grande interesse na gerontologia, porém, no Brasil, ainda existem poucos dados sobre o contexto do cuidado, o

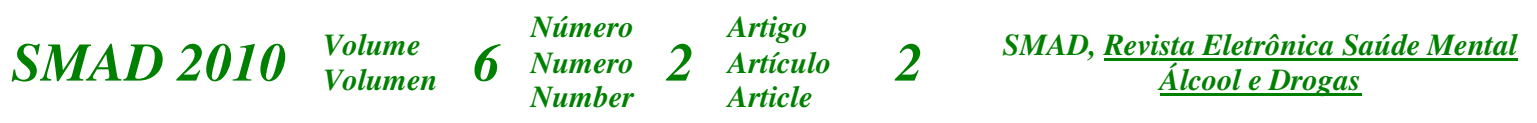



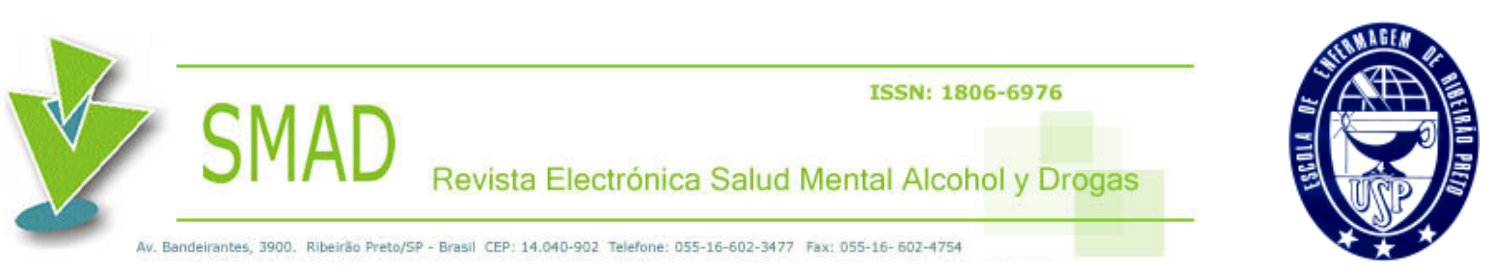

perfil dos cuidadores e as redes de apoio $^{(11)}$.

Pesquisas apontam que é possível perceber a preservação da saúde mental do cuidador familiar, através de experiências nas quais o mesmo se sente amparado, ao contar com apoio e em condições favoráveis para dar continuidade ao seu plano de vida, mediante a liberdade restabelecida ${ }^{(41)}$. Ao contrário do que acontece com a experiência daquele que não conta com apoio que, ao se sentir preso ao papel de cuidador, em face da insegurança de se afastar do doente, passa a conviver com muitas perdas pessoais.

Estudos revelam que os cuidadores que informam maior satisfação com o apoio que recebem e que estão inseridos em cadeias sociais maiores relatam menos sobrecarga ${ }^{(24)}$, menos depressão, maior satisfação com a vida e menos problemas de saúde ${ }^{(42)}$, em comparação aos cuidadores com menos laços sociais.

Quando mencionado anteriormente que o trabalho do cuidador torna-se tarefa solitária, recomenda-se aos profissionais de saúde que encarem a família como coadjuvante nos cuidados e não como empecilho aos mesmos. Que vejam a família como parceira em potencial, de forma a possibilitar a sistematização das tarefas, privilegiando aquelas relacionadas à promoção da saúde, prevenção das incapacidades e à manutenção da capacidade funcional do idoso e seu cuidador, evitando, dessa forma, hospitalizações, asilamentos, negligências e sobrecargas.

Os idosos e suas famílias merecem mais atenção tanto das autoridades públicas como dos profissionais da saúde. É importante que sejam efetivadas estratégias de proteção que se configurem como medidas que deem ao cuidador a possibilidade de planejar e de

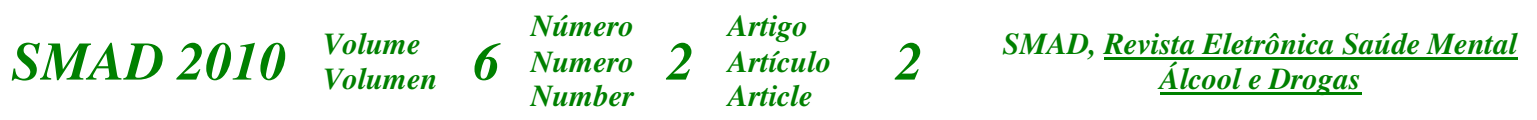



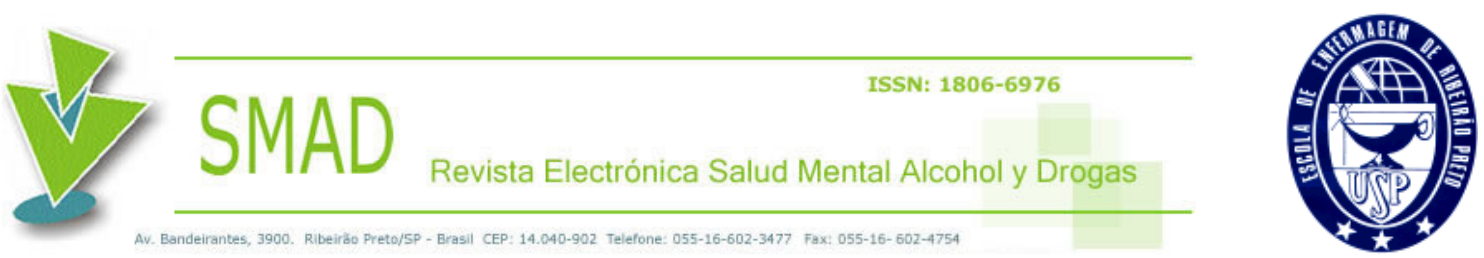

realizar outros interesses, com evitamento de colapso em sua vida.

E, dessa forma, proporcionar a esses "super-heróis" apoio e contentamento, para que se sintam valorizados e assistidos de forma digna, possibilitando que se percebam não como meros cuidadores, vivendo no anonimato, num domicílio qualquer, mas que existem pessoas envolvidas nesse processo, dispostas e capazes de ajudá-los ${ }^{(22)}$.

\section{Considerações Finais}

Se se pode afirmar que a atividade de cuidar tende a erodir a vida do cuidador, acarretando agravos significativos em sua saúde física e mental, e se considerando que essa atividade, além do cuidado, deva proporcionar bem-estar ao paciente, quais têm sido os investimentos em proteção e instrumentalização desse cuidador?

Esta pesquisa possibilitou confirmar, com base na revisão de literatura, a árdua e extenuante tarefa do cuidador, com sobrecarga de atividades no cotidiano que o leva, em muitas circunstâncias, ao estado de esgotamento emocional, isolamento social e situações de intensos conflitos, além da complexidade vivenciada no domicílio, com o idoso dependente e o contexto social onde estão inseridos. Também deixa evidente que os idosos dependentes e sem autonomia ainda fazem parte de uma face oculta da sociedade, porque, em muitos casos, são mantidos exclusivamente no âmbito familiar.

As mudanças presentes no envelhecimento populacional rápido e expressivo no

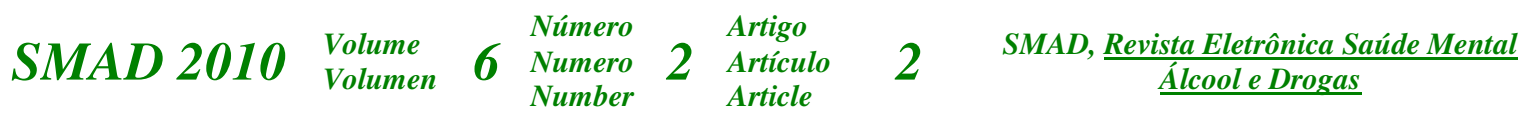



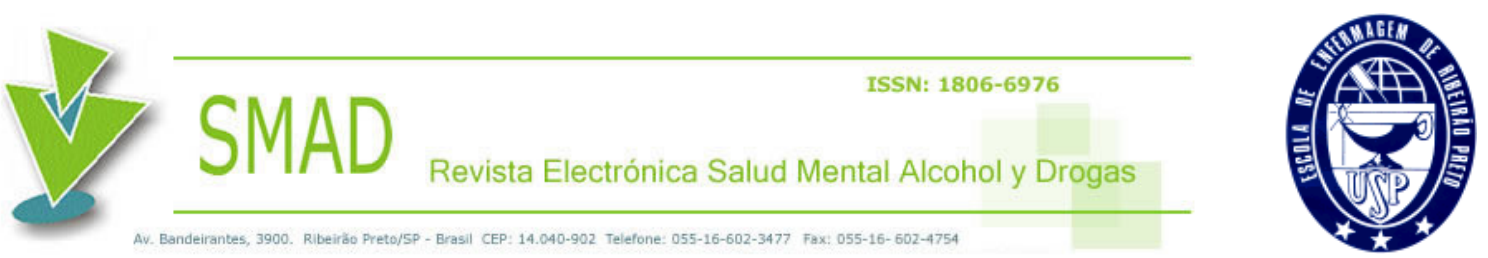

Brasil, no entanto, colocam caráter de urgência a busca de conhecimentos especializados. permitindo organizar ajuda a esses protagonistas do cuidado, visando seu bem-estar, através de estratégias que amenizem a realidade enfrentada por esses cuidadores.

Estratégias essas por meio de políticas sociais e de saúde, condizentes com as reais necessidades desse estrato populacional, onde o Estado tem papel preponderante na promoção, proteção e recuperação, conforme preconizado pelo Sistema Único de Saúde, desde planejamento dos cuidados no domicílio, com detecção precoce dos cuidadores e suas vulnerabilidades e intervenções, a fim de minimizar as dificuldades e sobrecarga das atividades do cuidado. E, ainda, viabilizando treinamento e acompanhamento como estratégia eficaz, programas de avaliação e de intervenções implementadas, continuadamente, por equipes de saúde, tendo em vista os benefícios potenciais para a saúde física e mental do cuidador e, consequentemente, a manutenção e promoção de cuidado a idosos dependentes.

\section{Referências}

1. Karsch UM. Idosos dependentes: famílias e cuidadores. Cad. Saúde Pública. 2003; 19(3):861-866. Disponível em: http://www.scielo.br/pdf/csp/v19n3/15890.pdf.

2. Silveira TM, Caldas CP, Carneiro TF. Cuidando de idosos altamente dependentes na comunidade: um estudo sobre cuidadores familiares principais. Cad. Saúde Pública. 2006;

$$
\text { SMAD } 2010 \begin{aligned}
& \begin{array}{l}
\text { Volume } \\
\text { Volumen }
\end{array} \\
& \text { SMumer }
\end{aligned} \quad \begin{aligned}
& \begin{array}{l}
\text { Número } \\
\text { Numero } \\
\text { Number }
\end{array} \\
& 2
\end{aligned} \begin{aligned}
& \begin{array}{l}
\text { Artigo } \\
\text { Artículo } \\
\text { Article }
\end{array} \\
& \text { SMAD, Revista Eletrônica Saúde Mental }
\end{aligned}
$$



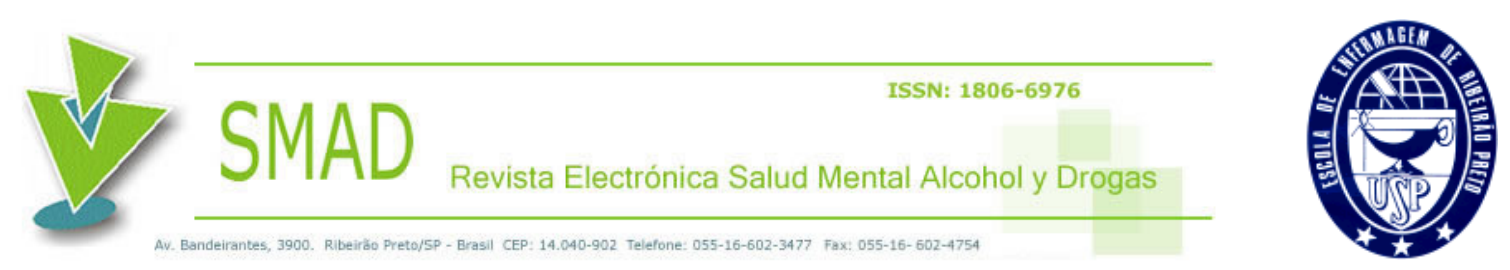

22(8):1629-1638. Disponível em: http://www.scielosp.org/scielo.php?pid=S0102-

\section{$\underline{311 X 2006000800011 \& \text { script=sci_abstract\&tlng=e. }}$.}

3. Almeida TL. Características dos cuidadores de idosos dependentes no contexto da saúde da família [Dissertação]. Ribeirão Preto: Faculdade de Medicina de Ribeirão Preto; 2005.

4. Neri AL. Bem-estar e estresse em familiares que cuidam de idosos fragilizados de alta dependência. In: Neri AL, organizador. Qualidade de vida e idade madura. Campinas: Papirus; 1993.

5. Perracini, MR, Neri AL. Tarefas de cuidar: com a palavra, mulheres cuidadoras de idosos de alta dependência. In: Neri AL, organizador. Cuidar de idosos no contexto da família: questões psicológicas e sociais. Campinas: Alínea; 2002. p. 135-163.

6. Diogo MJE, Duarte YAO. Cuidados em domicílio: conceitos e práticas. In: Freitas EV et al. Tratado de geriatria e gerontologia. Rio de Janeiro: Guanabara Koogan; 2002.

7. Leite RCBO. O idoso dependente em domicílio [Dissertação]. Salvador: Faculdade de Enfermagem da Universidade Federal da Bahia; 1995.

8. Medina C, Shirassu M, Goldfeder M. Das incapacidades e do acidente cerebrovascular. In: Karsch UM, organizador. Envelhecimento com dependência: revelando cuidadores. São Paulo: EDUC; 1998. p. 199-214.

9. Hooyman NL, Kyak HA. Social gerontology: a multidisciplinary perspective. 4 ed. Boston: Allyn \& Bacon; 1996.

10. Neri AL, Sommerhalder, C. As várias faces do cuidado e do bem-estar do cuidador. In: Neri AL, organizador. Cuidar de idosos no contexto da família: questões psicológicas e SMAD $2010 \begin{aligned} & \begin{array}{l}\text { Volume } \\ \text { Volumen }\end{array} \\ & \text { SMumero }\end{aligned} \quad \begin{aligned} & \begin{array}{l}\text { Número } \\ \text { Number }\end{array} \\ & \text { Numbrtículo }\end{aligned} \quad \begin{aligned} & \begin{array}{l}\text { Artiog } \\ \text { Article }\end{array} \\ & \text { SMAD, Revista Eletrônica Saúde Mental }\end{aligned}$ 

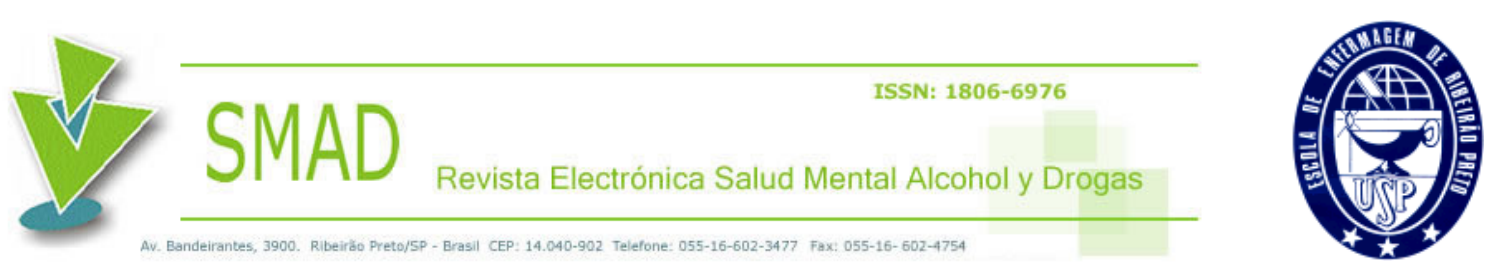

sociais. Campinas: Alínea; 2002, p. 9-63.

11. Yuaso DR. Cuidar de cuidadores: resultados de um programa de treinamento realizado em domicílio. In: Neri AL, organizador. Cuidar de idosos no contexto da família: questões psicológicas e sociais. Campinas: Alínea; 2002. p. 164-201.

12. Ramos LR. Epidemiologia do envelhecimento. In: Freitas EV et al. Tratado de geriatria e gerontologia. Rio de Janeiro: Guanabara Koogan; 2002. p. 72-78.

13. National Alliance for Care Giving and AARP. Family care giving in the US: findings from a national survey, national alliance for care giving. Washington, DC, 1997.

14. Leme MD. Treinamento de cuidadores de idosos: impacto na sua qualidade de vida e saúde [Dissertação]. São Paulo: Faculdade de Medicina da Universidade de São Paulo; 2006.

15. Baum ME, PAGE M. Caregiving and multigerational families. The gerontologist. 1991; 31(6): 762-769.

16. Floriani CA, Schramm FR. Cuidador do idoso com câncer avançado: um ator vulnerado. Cad. Saúde Pública. 2006 mar.; 22(3):527-534. Disponível em: http://www.scielo.br/pdf/csp/v22n3/07.pdf.

17. Neri AL, organizador. Cuidar de idosos no contexto da família: questões psicológicas e sociais. Campinas: Alínea; 2002.

18. Angelo M. Com a família em tempos difíceis: uma perspectiva de enfermagem [Tese Livre Docência]. São Paulo: Escola de Enfermagem da Universidade de São Paulo; 1997.

19. Mendes PBMT. Cuidadores: heróis anônimos do cotidiano [Dissertação]. São Paulo:

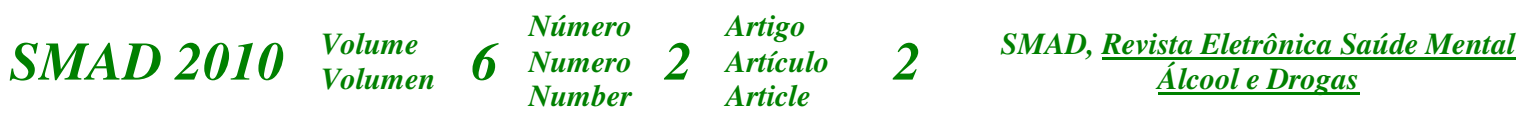



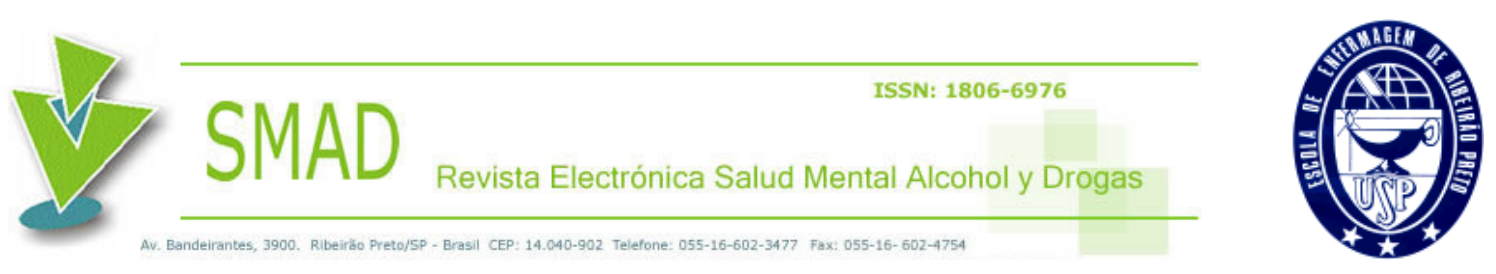

Faculdade de Ciências Sociais da Pontifícia Universidade Católica; 1995.

20. Morycz R. Caregiving families and cross-cultural perspectives. In: Zarit SH, Pearlin

EK, Schaie W, editores. Caregiving systems: informal and formal helpers. Hillsdale: Lawrence Erlbaum Associates; 1993.

21. Bandura A. Social fondations of thougth and action: a social cognitive approach. Englewood Cliffs, NJ: Prentice Hall; 1986.

22. Cattani RB, Girardon-Perlini NM. O. Cuidar do idoso doente no domicílio na voz de cuidadores familiares. Rev. Eletrônica de Enfermagem. 2004; 6(2):254-271. Disponível em: http://www.fen.ufg.br/revista/revista6_2/idoso.html.

23. Pearlin LJ, Mullan JT, Semples SJ, Skaff MM. Caregiving and the stress process: an overview of concepts and their measures. The gerontologist. 1990; 30(5):583-591.

24. Vitalino PP, Young HM, Russo J. Burden: a review of measures used among caregivers of individuals with dementia. The gerontologist. 1991; 31(1):67-75.

25. Dillehay RC, Sandys MR. Caregivers for Alzheimer's patients: what we are learning from research. International Journal of Aging Human Development. 1990; 30:263-285.

26. Matsuda CMCB. Sobrecarga e saúde mental em cuidadores de idosos com demência ou com depressão [Dissertação]. São Paulo: Faculdade de Medicina da Universidade de São Paulo; 2004.

27. Donaldson C, Tarrier N, Burns A. The impact of the symptoms of dementia patients on caregivers. Br J Psychiatry. 1997; 170:62-68.

28. Freitas EV, Py L, Neri AL, Cançado FAX, Gorzoni ML, Rocha SM. Tratado de

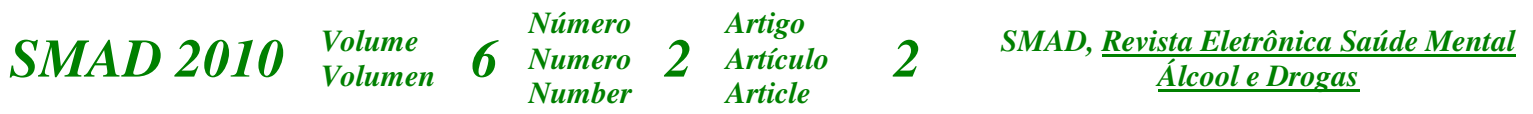



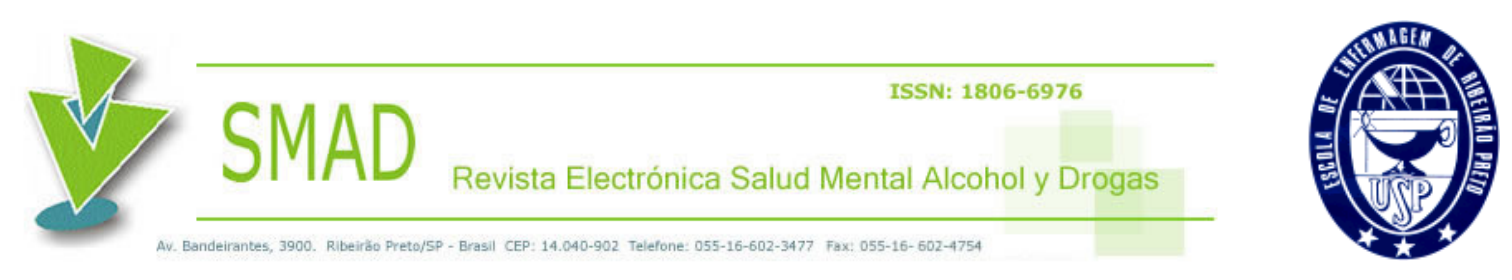

geriatria e gerontologia. Rio de Janeiro: Guanabara Koogan; 2002.

29. Hoenig J, Hamilton M. The schizophrenic patient in the community and his effect on the household. Int J Soc Psychiatry. 1966; 12:165-176.

30. Thompson Jr EH, Doll W. The burden of families coping with the mentally ill: as invisible crisis. Farm Relat. 1982; 31:379-388.

31. Pavarini SCI, Neri AL. Compreendendo dependência, independência e autonomia no contexto domiciliar. In: Duarte IAO, D'élboux DMJ, organizadores. Atendimento domiciliar: um enfoque gerontológico. São Paulo: Atheneu; 2000. p. 49-70.

32. Karsch UM, organizador. Envelhecimento com dependência: revelando cuidadores. São Paulo: EDUC; 1998.

33. Gallagher-Thompson $\mathrm{D}$ et al. Chance in indices of distress among latino and anglo female caregivers of elderey relatives with dementia: sitc-especific results from the reach national collaborative study gerontologist. 2003; 43(4):580-591.

34. Cohen D, Shaw H. Caring for relatives with Alzheimer's disease: the mental health risks to spouses, adult children, and other family caregivers. Behavior, health and aging. 1990; 1(3):171-182.

35. Sena RR, Silva KL, Rates HF, Vivas KL, Queiroz CM, Barreto FO. O cotidiano da cuidadora no domicílio: desafios de um fazer solitário. Cogitare Enfermagem. 2006; $11(2) ; 124-132$. Disponível

em: http://ojs.c3sl.ufpr.br/ojs2/index.php/cogitare/article/view/6854/4868.

36. Silva IP. As relações de poder entre o adulto dependente e a mulher cuidadora SMAD $2010 \begin{aligned} & \text { Volume } \\ & \text { Volumen }\end{aligned} \quad 6 \begin{aligned} & \begin{array}{l}\text { Número } \\ \text { Numero } \\ \text { Number }\end{array} \\ & \text { Sulticle }\end{aligned} \quad \begin{aligned} & \begin{array}{l}\text { Artigo } \\ \text { Artículo } \\ \text { Article }\end{array} \\ & \text { SMAD, Revista Eletrônica Saúde Mental }\end{aligned}$ 

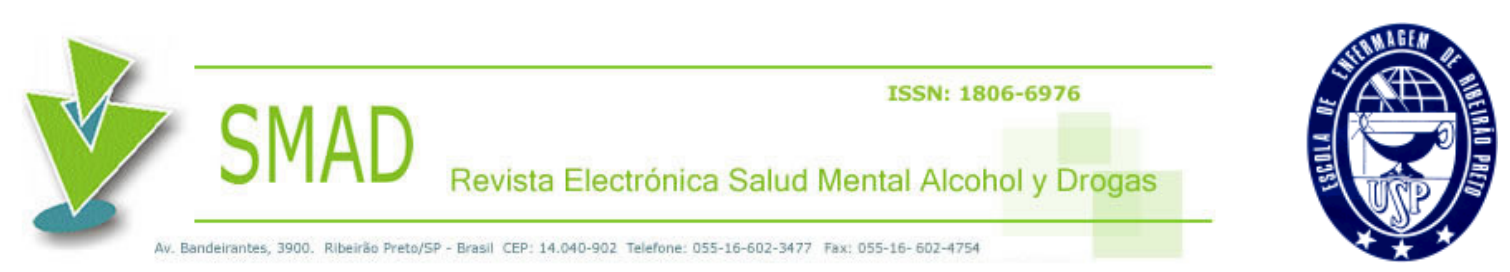

[Dissertação]. São Paulo: Faculdade de Ciências Sociais da Pontifícia Universidade Católica; 1995.

37. Yuaso DR. Treinamento de cuidadores familiares de idoso de alta dependência em acompanhamento domiciliário [Dissertação]. Campinas: Universidade Estadual de Campinas; 2000.

38. Pereira MJB, Mishima SM, Fortuna CM, Matumoto S, Teixeira RA, Ferraz CA, et al. Assistência domiciliar: instrumento para potencializar processo de trabalho na assistência e na formação. In: Barros ARF, organizador. Observatório de Recursos Humanos em Saúde no Brasil: estudos e análise. Brasília: Ministério da Saúde; 2004. v. 2, p. 71-80.

39. Martins JJ, Albuquerque GL, Nascimento ERP, Barra DCC, Souza WGA, Pacheco WNS. Necessidades de educação em saúde dos cuidadores de pessoas idosas no domicílio. Texto Contexto Enferm. 2007; 16(2):254-262. Disponível em: http://www.scielo.br/pdf/tce/v16n2/a07v16n2.pdf.

40. Yuaso DR, Sguizzatto GT. Serviço de assistência domiciliária ao idoso do centro de referência à saúde do idoso do município de Guarulhos. In: Duarte YAO, DIOGO MJD, organizadores. Atendimento domiciliar: um enfoque gerontológico. São Paulo: Atheneu; 2000.

41. Angelo M, Bocchi SCM. Entre a liberdade e a reclusão: o apoio social como componentes da qualidade de vida do binômio cuidador familiar-pessoa dependente. Rev. Latino-Am. Enfermagem. 2008; 16(1):15-23. Disponível em: http://www.scielo.br/pdf/rlae/v16n1/02.pdf.

SMAD $2010 \begin{aligned} & \text { Volume } \\ & \text { Volumen }\end{aligned} \quad 6 \begin{aligned} & \begin{array}{l}\text { Número } \\ \text { Numero } \\ \text { Number }\end{array} \\ & \text { Sulticule }\end{aligned} \quad \begin{aligned} & \begin{array}{l}\text { Artigo } \\ \text { Artículo } \\ \text { Article }\end{array} \\ & \text { SMAD, Revista Eletrônica Saúde Mental }\end{aligned}$ 
42. Haley WE, Levine EG, Brown SL, Bartolucci AA. Stress, appraisal, coping, and social support as predictors of adaptational outcome among dementia caregivers. Psychol Agig. $1987 ; 2: 323-330$.

Recebido em: 14/08/2009

Aprovado em: 04/04/2010

\section{Como citar este artigo:}

Camargo RCVF. Implicações na saúde mental de cuidadores de idosos: Uma necessidade urgente de apoio formal. SMAD, Rev. Eletrônica Saúde Mental Álcool Drog. (Ed. port.) [Internet]. 2010 [acesso em: dia mês abreviado com ponto ano] ; 6(2):231-54. Disponível em: Endereço Eletrônico Visitado.

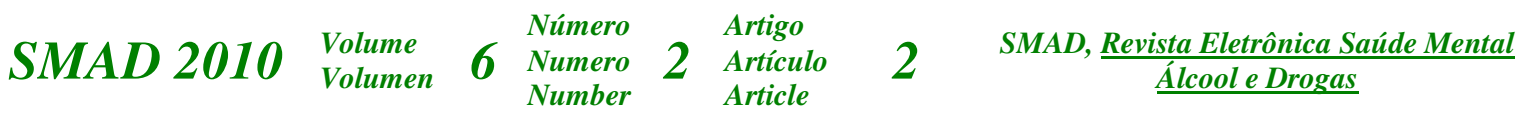

